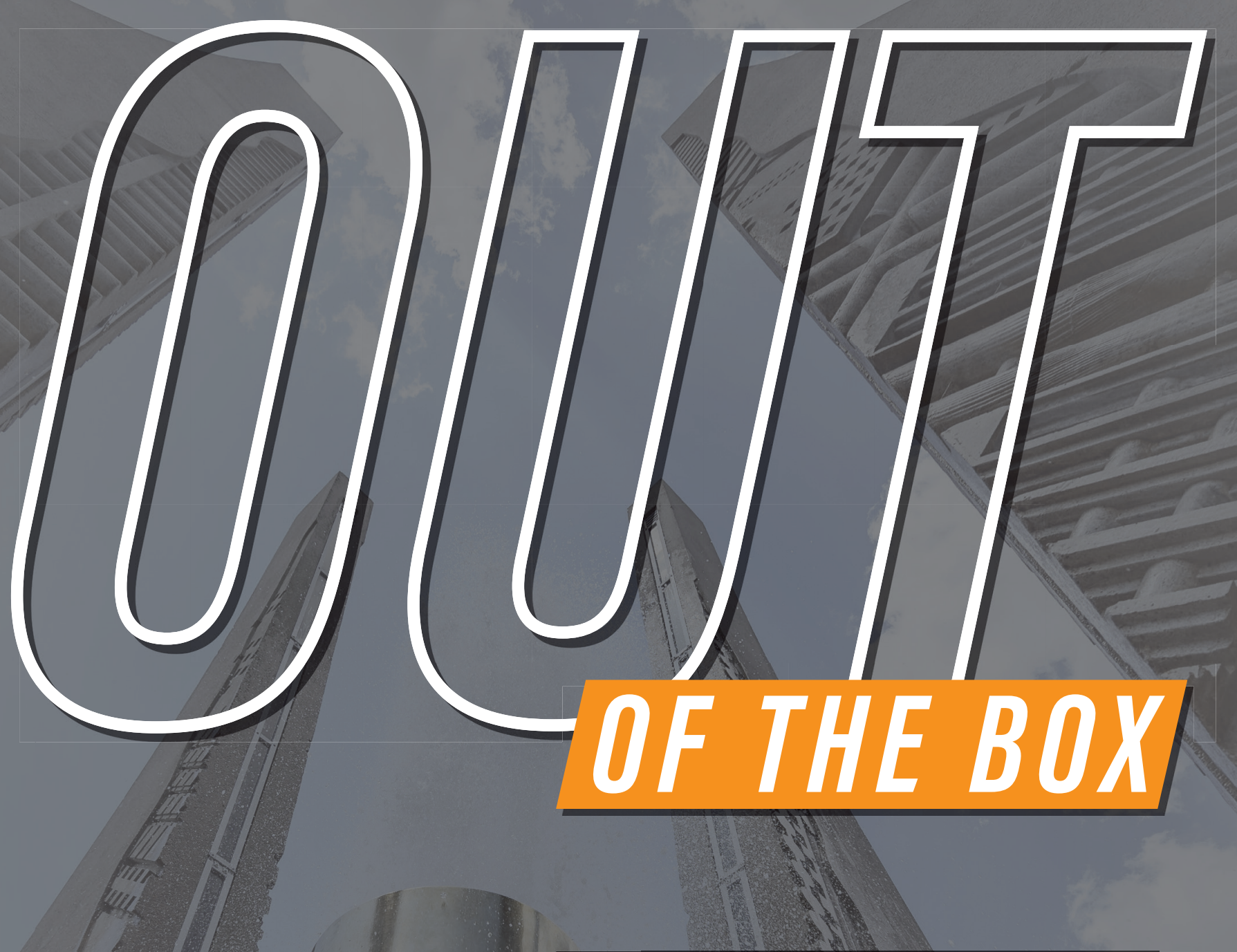

Out of the Box

pieces from

undergraduates

demonstrate

hands-on research

in action, often with

real-world impacts. 


\section{AN INSIDE LOOK AT THE JPUR PUBLICATION PROCESS}

\section{Journal of Purdue Undergraduate Research Coordinator Ethan Edwards outlines the production of JPUR and the benefits of publishing as an undergraduate.}

\section{The Value of Scientific Research}

Parents, peers, government organizations, and Fortune 500 companies: the variety of Journal of Purdue Undergraduate Research (JPUR) readers creates a constant challenge in producing an impactful annual publication. Nearly one-fourth of the journal's online reads come from a global audience, as shown in Figure 1. For the students from Purdue University and our satellite campuses who are accepted to publish their research, the main goal is ensuring their published work, no matter the discipline, is understandable to a general audience.
As journal coordinator for volumes 10 and 11 of JPUR, I was involved in a variety of behind-the-scenes work including marketing, training student editors, coordinating with faculty reviewers, and much more. One of the top priorities of our annual undergraduate research publication is to improve scientific communication at Purdue, and I made that a focal point in my time as journal coordinator. Scientific communication may be defined as a variety of practices that transmit scientific ideas, methods, knowledge, and research to nonexpert audiences in an understandable way. As an example, how well would a history student with no discipline-specific training understand technical engineering research on water filters? Ideally, the writing would be tailored to the level of the reader. This priority aligns well with Purdue's land-grant status. Land-grant universities were formed to have direct benefit to society. JPUR's open access model embodies the land-grant spirit as anyone outside of the university can easily download and learn about the work being conducted at Purdue, grasp the relevance of the research, and ideally apply the key takeaways to their respective fields.

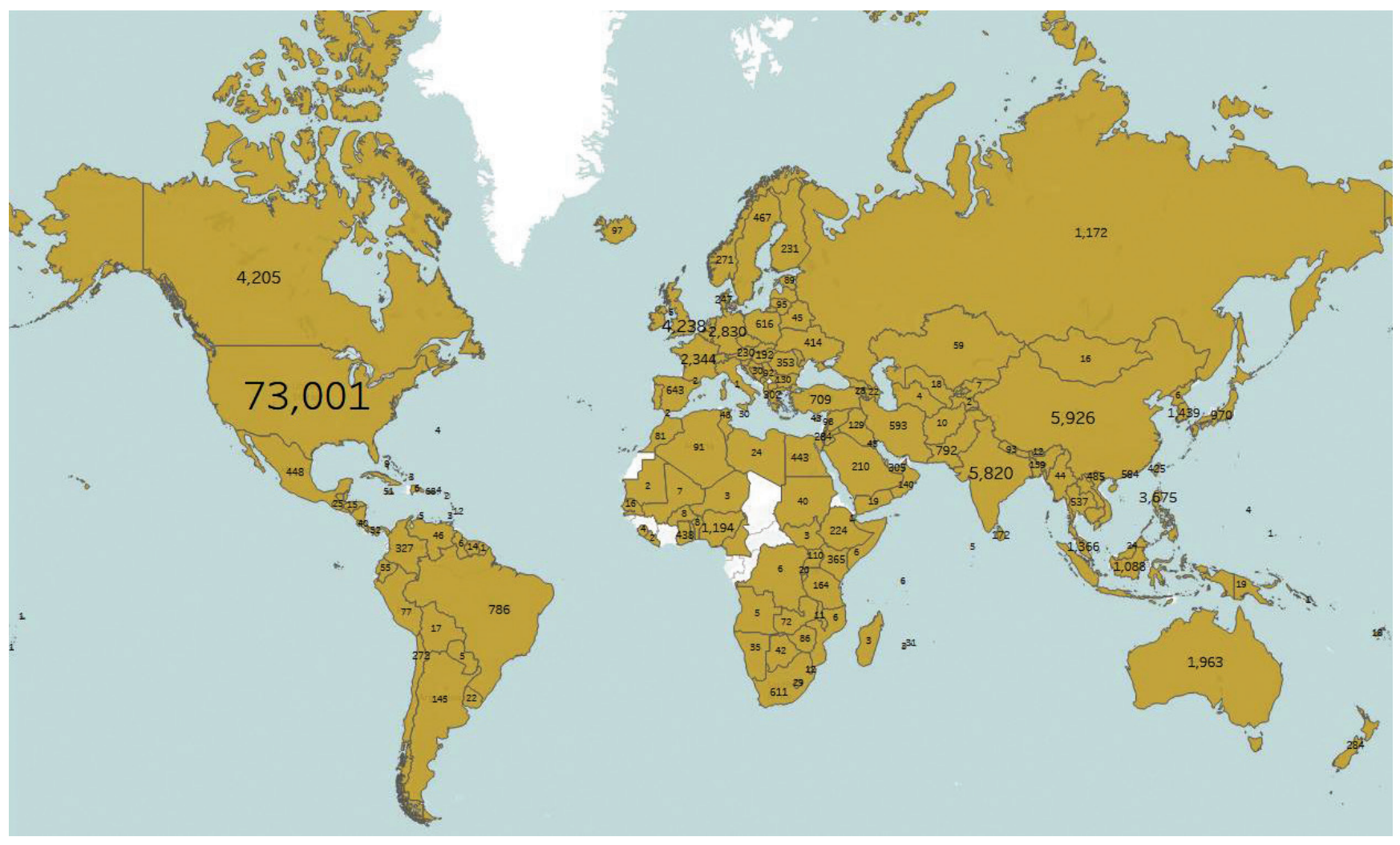

FIGURE 1. Visualization of JPUR downloads from around the world. 
Understanding an audience is imperative to communication. Outside of my work managing JPUR, I was involved in drinking water research at Purdue. Safe drinking water is a fundamental necessity of life, and many people rely on community water systems for their water. However, there are a multitude of challenges that must be faced: water affordability, emerging contaminants that must be removed from water systems, and aging water infrastructure is all a part of a nonexhaustive list that a community water system could need to deal with. Community water systems are required to publish a Consumer Confidence Report, which is an annual drinking water quality report required by the Environmental Protection Agency (EPA). This report is supposed to inform community water system's consumers about their water quality, but it is often an inaccessible and hard-to-understand document.

According to The Literacy Project, the average American reads at a 7th- to 8th-grade level, which is what is recommended for public health communication. In comparison, a 2010 example model of the Consumer Confidence Report on the EPA website scored an 11.3 reading grade level, much higher than the recommended reading level (Roy, 2015). Recognizing the need for improvement, the EPA passed a rule requiring changes to the content, manner, and frequency of these reports to improve communication in 2018. In summary, making water quality data understandable and accessible to most people is a challenge, especially because many water operators and engineers who are writing these documents may not have had formal training on scientific communication. These challenges are prevalent in many fields and must be addressed.

There are a multitude of reasons why a student researcher may choose to publish in JPUR. They may be interested in gaining a firsthand experience in the scholarly publishing process, having a closer connection with their faculty mentor and graduate student advisors, or showcasing their work to graduate schools or future employers. However, I believe an underrated benefit is the opportunity to practice one's scientific communication skills. Consider the advice of JPUR alumna Marisa Henry, now a Gates Cambridge Scholar and data scientist, who was asked in JPUR volume 10's spotlight how the undergraduate research and publishing experience influenced her current endeavors:

"ALTHOUGH THE DAY-TO-DAY WORK OF CONDUCTING RESEARCH DIFFERS FROM MY WORK AS A DATA SCIENTIST, BOTH ARE UNDERPINNED BY SIMILAR SKILLS: AN ABILITY TO ASK INTERESTING QUESTIONS, IMPLEMENT APPROPRIATE SCIENTIFIC METHODS TO ADDRESS THOSE QUESTIONS, AND EFFECTIVELY COMMUNICATE TECHNICAL RESULTS (SOMETIMES TO A NONTECHNICAL AUDIENCE)."

\section{JPUR Timeline and Publication Process}

When JPUR was first established in 2010, the goal was to further encourage the development of undergraduate research at Purdue by showcasing the best work in a tangible, centralized, and public way. One of the key factors that reviewers consider when accepting articles and snapshots is the author's ability to connect to a general audience. Proposals that are reader-friendly and engage a multidisciplinary readership often find the most success. JPUR authors are welcome to submit their faculty-mentored research at any point as a student and in the year following their graduation. Many students also submit in small groups or publish research that developed out of a course.

There are many steps that occur between the proposal submission and the final publication, and the JPUR process truly begins prior to the proposal submission. The proposal is a short series of questions that prompts the student researcher to describe the impact of their research project, what methods they are undertaking to answer the research question, what new knowledge they have created through the project, and what their role in the research was. When developing the proposal, students are encouraged to interface with their faculty advisor, graduate student advisor, the Purdue 
Writing Lab, and JPUR staff for feedback and advice. In the past, JPUR has offered in-person office hours, writing workshops, an online feedback form for drafts, and email support.

After the proposals are submitted before the November 15 fall deadline or the February 15 spring deadline, each proposal receives a comprehensive review by two Student Editorial Board members and a faculty reviewer from the student's discipline. These reviews include suggested changes and recommendations for how a student can develop the work into a finished product. Next, the Faculty Advisory Board and Purdue University Press staff make final decisions regarding what proposals are fit for articles, snapshots, or need to be revised and resubmitted, and offer their own insights into the student work. Often these suggested edits are focused on how the work can be connected to a broad audience and made more understandable.

At this point, authors receive a trained Student Editorial Board member to guide them through the writing process. Their work is due in April to allow for ample time for production of the volume over the summer. The production phase includes their work being reviewed once more by professional copy editors and typeset before final publication, which occurs in August of every year.

\section{Assessment of Current Readability}

Having a better understanding of the journal's current reading level will help improve our peer review and publishing process. Well-established readability metrics such as the Gunning Fog Index, the Flesch-Kincaid Grade Level, and Dale-Chall Scores can assist in assessing JPUR's current level. A $13^{\text {th }}$ grade reading level corresponds to a first-year undergraduate student, and a $17^{\text {th }}$ grade reading level equates to a college graduate, as shown in Table 1. Ideally, published work would not exceed the $17^{\text {th }}$ grade reading level.

Abstract texts were collected from JPUR snapshots and articles from JPUR volume 10 (2020), articles from the Indiana Journal of Undergraduate Research (IUJUR) volume VI (2020), and oral presentations from the Purdue Office of Undergraduate Research (OUR) spring 2020

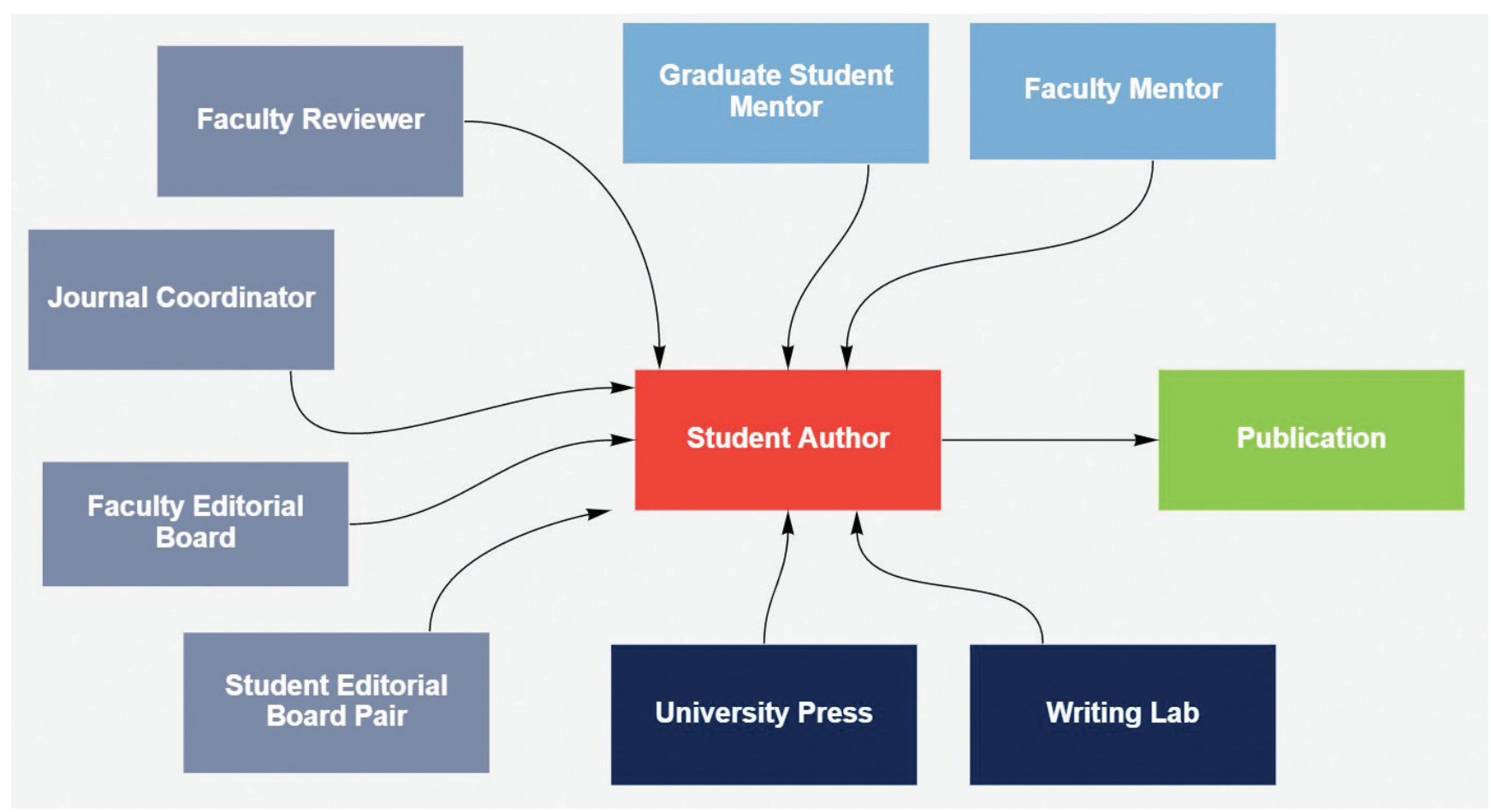

FIGURE 2. Student authors receive support from a variety of stakeholders and involved campus groups to assist them in developing a final publication. 
TABLE 1. Reading grade levels in the Flesch-Kincaid metric.

\begin{tabular}{|c|l|}
\hline Flesch-Kincaid Level & Reading Level \\
\hline 17 & College Graduate \\
\hline 16 & College Senior \\
\hline 15 & College Junior \\
\hline 14 & College Sophomore \\
\hline 13 & College Freshman \\
\hline 12 & High School Senior \\
\hline 11 & High School Junior \\
\hline 10 & High School Sophomore \\
\hline 9 & High School Freshman \\
\hline 8 & Eighth Grade \\
\hline 7 & Seventh Grade \\
\hline
\end{tabular}

conference. These texts were plugged into an online readability analyzer (Datayze) to quantify the level with the Flesch-Kincaid Grade Level, and the results were tabulated and sorted into various categories such as the college or discipline of the abstract.

After analyzing over 100 published abstracts, it was found that IUJUR and JPUR articles were the most challenging to read, coming in close to a 17 th grade reading level. JPUR snapshots were the most readable at a 13.9 reading level, and OUR abstracts were similarly ranked at 14.5. These results may be visualized in Figure 3. All reading levels fell between the college freshman and college senior levels, which is ideal for the general college audience that the journals are geared toward.

When separated by discipline, published work from Purdue Polytechnic and the College of Education were the hardest to read, while work from the College of Health and Human Sciences was the most readable, as shown in Figure 4.

These results provide interesting insights, especially when considering the context of JPUR's volume 10 annual audit, which surveys student authors to gauge their experience and perceived learning gains. The audit was conducted on the same dataset that was used for analysis, and it revealed that learning gains were seen across most competencies by all student authors, with article authors reporting more increases. All article authors noted improved understanding of how to write about research for an informed public audience, as opposed to just a third of snapshot authors. Nearly all article authors also reported gains in how to write for a professional publication and in understanding the process for publishing an article, yet similar gains were only seen in approximately half of snapshot authors.

The difference between articles and snapshots could be attributed to articles having a more involved writing process due to the differences in length. Going forward,

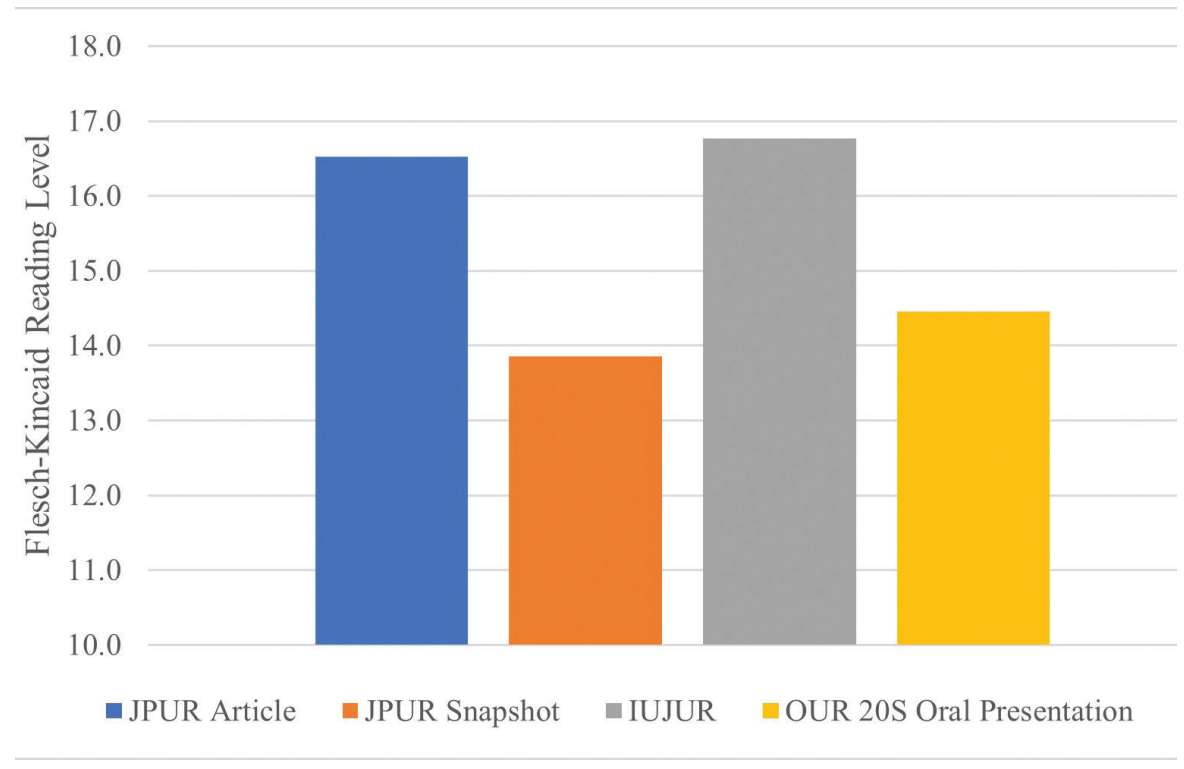

FIGURE 3. Variation of Flesch-Kincaid Grade Level among disciplines. 


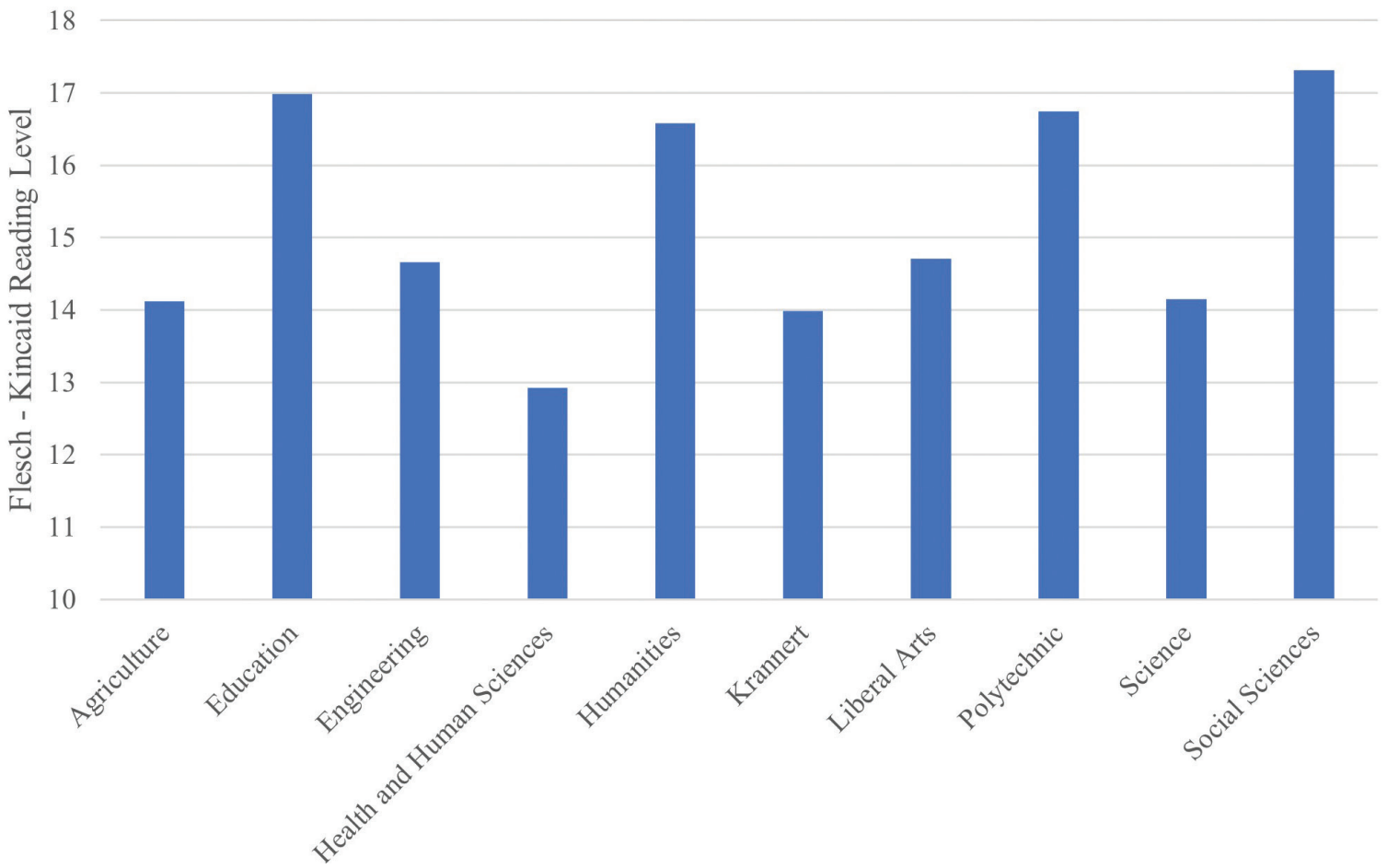

FIGURE 4. Variation of Flesch-Kincaid Grade Levels across Purdue colleges.

specific attention could be given to snapshot authors and those authors in the education and social science disciplines to ensure learning gains occur. Similarly, article authors may need tailored insights to ensure that their work remains readable. Future journal coordinators of JPUR will be tasked with continuing to develop new training materials for all authors and connecting students with various resources.

\section{References}

Datayze Readability Analyzer. (2021). Datayze Readability Analyzer. https://datayze.com/readability-analyzer IU Journal of Undergraduate Research. (2020). Indiana University Journal of Undergraduate Research, 6, https://scholarworks .iu.edu/journals/index.php/iujur

Journal of Purdue Undergraduate Research. (2020). Journal of Purdue Undergraduate Research, 10, https://docs.lib.purdue.edu/jpur

Roy, S., Phetxumphou, K., Dietrich, A. M., Estabrooks, P. A., You, W., \& Davy, B. M. (2015). An evaluation of the readability of drinking water quality reports: A national assessment. Journal of Water and Health, 13(3), 645-653. https://doi .org/10.2166/wh.2015.194

\section{Student Author}

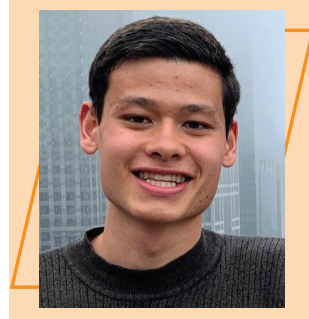

ETHAN EDWARDS is a senior in Purdue's Honor College studying civil engineering with an environmental concentration. Edwards served as the coordinator for this volume and volume 10 of the Journal of Purdue

Undergraduate Research and on the Student Editorial Board for volumes 8 and 9. He is also involved with the Purdue Running Club, acts as a Lyles School of Civil Engineering Ambassador, and serves as the President of Purdue's Chapter of the American Water Works Association. 